\title{
Qualitative Evaluation of a Professional Training: Community Health at Alioune Diop University in Bambey (UADB)
}

\author{
Ousseynou Ka ${ }^{1,}$ *, Mountaga Elimane Dia ${ }^{1}$, Fatou Oumar Ndiaye Sy ${ }^{1}$, Abdoul Aziz Ndiaye ${ }^{1}$, \\ Ndeye Fatou Ngom Gueye ${ }^{2}$, Aladji Madior Diop ${ }^{3}$, Cheikh Tacko Diop ${ }^{1}$, Martial Coly Bop ${ }^{1}$, \\ Boubacar Gueye $^{1}$, Alioune Badara Tall ${ }^{1}$, Papa Gallo Sow ${ }^{1}$, Abdou Khaly $\operatorname{Mbodj}^{1}, \operatorname{Lamine}$ Guéye $^{4}$ \\ ${ }^{1}$ Community Health Department, Health and Sustainable Development Training and Research Unit, Alioune Diop University, Bambey, \\ Senegal \\ ${ }^{2}$ Médecine Department, Health and Sustainable Development Training and Research Unit, Alioune Diop University, Bambey, Senegal \\ ${ }^{3}$ Sustainable Development Department, Health and Sustainable Development Training and Research Unit, Alioune Diop University, Bambey, \\ Senegal \\ ${ }^{4}$ Physiology Department, Faculty Medicine, Pharmacy and Odontology, Cheikh Anta Diop University, Dakar, Senegal
}

\section{Email address:}

ousseynou.ka@uadb.edu.sn (Ousseynou Ka)

${ }^{*}$ Corresponding author

\section{To cite this article:}

Ousseynou Ka, Mountaga Elimane Dia, Fatou Oumar Ndiaye Sy, Abdoul Aziz Ndiaye, Ndeye Fatou Ngom Gueye, Aladji Madior Diop, Cheikh Tacko Diop, Martial Coly Bop, Boubacar Gueye, Alioune Badara Tall, Papa Gallo Sow, Abdou Khaly Mbodj, Lamine Guéye. Qualitative Evaluation of a Professional Training: Community Health at Alioune Diop University in Bambey (UADB). World Journal of Public Health. Vol. 6, No. 2, 2021, pp. 45-51. doi: 10.11648/j.wjph.20210602.14

Received: February 20, 2021; Accepted: May 5, 2021; Published: May 27, 2021

\begin{abstract}
Introduction: Health training community is based on a professionalizing approach which consists of placing on the job market community health professionals with know-how and able to meet the needs of the populations. Goals: Assess with community health professionals the level of adequacy of theoretical and practical training in the field of their training and with employers, the quality and relevance of the skills retained within the framework of the teaching / learning program of these professionals. Methods: This is a qualitative study carried out from February 1 to April 15, 2020, targeting community health professionals (semi-structured interviews) et employers (focus group). The content analysis of the speeches illustrated by the words put in quotation marks by the people surveyed was carried out. Results: Community health professionals have affirmed that there is an adequacy between theoretical and practical training in the field and internships in care and community settings have greatly contributed to making this training professional. The professionalizing nature of this training is confirmed by the employers, that is to say the officials of the Ministry of Health and Social Action but also by non-governmental organizations. They underlined the usefulness of these professionals in the health system. The training model is co-constructed between teachers and employers and the latter's concerns are taken into account. Community health professionals consider it essential to revisit the training model and adapt it to the context of the country. So, it has been proposed to eliminate certain teaching units, to strengthen others, but above all to integrate certain topical issues. With regard to professional integration, it was noted that it is more easily done at the level of non-governmental organizations (NGOs) than at the level of the Ministry of Health and Social Action. Conclusion: Recommendations were formulated for a revision of the model in order to make the training more adapted to the needs of the market, as well as the recruitment of graduates by the Ministry of Health and Social Action.
\end{abstract}

Keywords: Community Health, Community Health Professionals, Vocational Training, Professional Integration, Training Model 


\section{Introduction}

Based on the observation that prevention was insufficiently taken into account in the health care system and that in terms of health nothing can be done without the community, the academic authorities of the Ministry of Higher Education, Research and Innovation from Senegal decided to set up a diploma course in community health at the Alioune Diop University in Bambey in 2007 [1]. Their concern was to diversify the training offer through innovative training that meets the needs of populations and the job market. These community health professionals do not should not be confused with "CHW" community health workers even if there are similarities in their activities. A community health worker "ASC" is a member of the community chosen by the latter, who has received basic training to promote health or to practice certain health care services, without being a health professional. [2, 3]. Moreover, it is the MSAS which defines the promotional, preventive, curative and re-adaptive activities to be entrusted to CHWs and these can only be implemented under the supervision of qualified health workers (doctors, nurses, midwives, etc.). On the other hand, community health professionals like paramedics (nurses, midwives, etc.) benefit from diploma training and work for and with the community. This unique training in the West African region has for objective of putting community health professionals on the labor market capable, through a participatory approach, of identifying a priority health problem in a community, of providing suitable solutions and of evaluating the interventions carried out. Thus, community health $[4,5]$ is defined as an approach to solving health problems based on the participation and engagement of communities. This approach based on the support of enlightened public opinion and active cooperation from communities need a transfer of knowledge and skills from community health professionals to these communities so that they can play and fully assume their function with the aim of empowering them [6, 7]. This training fills a gap in qualified human resources, since community health activities were "insufficiently" carried out by doctors specializing in public health and by paramedics from the public sector. Indeed, the latter were more concerned with administrative tasks and patient care than with promotional and preventive health activities. These community health graduates, holders of bachelor's or master's degrees generally recruited in the health sector, most often work at the level of health districts (public sector) but also at the level of non-governmental organizations "NGOs". This political will to adopt a community approach [8] by our health authorities in disease control programs was reinforced by the creation in 2012, at the Ministry of Health and Social Action "MSAS", of a community health unit [9]. Our study aimed to assess with community health professionals the level of adequacy between theoretical and practical training in the field, professional integration... and with employers the quality and relevance of the skills retained within the framework of the program teaching / learning of these professionals.

\section{Methods}

\subsection{Study Framework}

The community health system follows the pyramidal architectural organization of the Senegalese health system made up of three levels $[9,10]$. At the central level, there is the community health unit which is housed at the level of the General Directorate of Health of the MSAS. She had to develop strategic documents such as the National Community Health Policy "PNSC" and the National Strategic Plan for Community Health "PSNSC" The objective of this PNSC is to contribute to the reduction of morbidity and mortality with full participation of communities. While the PSNSC, a tool for implementing the PNSC, aims to systematize, organize and coordinate all community interventions throughout the national territory. At the intermediate level, the medical region which is the level of supervision and coordination at the regional level of community health activities. The medical region is headed by a chief medical officer specializing in public health supported by the "ECR" regional team, including among others a community health supervisor. At the peripheral level, the health district which is a level of execution of community health activities. The district is an operational zone comprising at least one health center, health posts and sometimes health huts. The district is also headed by a doctor specializing in public health supported by the district management team "ECD" including among others a focal point in community health. The function of EDC or EDC is administrative and financial management, supervision, staff training, planning, monitoring and evaluation of health activities in the region or district. Community activities benefit from financial and logistical support from civil society organizations and development partners. Formally, these activities are planned in the same way as the activities of health centers and posts through the operational plans of local communities [10].

\subsection{Type of Study}

This is a study based on a qualitative approach carried out during the period from February 1 to March 15, 2020.

\subsection{Study Population}

It focused on two targets: community health graduates integrated into a professional environment and their employers.

\subsection{Data Collection}

The collection was carried out by two community health professionals with a master's degree, one of whom is enrolled in a doctorate. They work in non-governmental organizations "NGOs" and have professional experience in data collection. 
The interviews were recorded using a Dictaphone and then transcribed after collection. The working language was French. Two tools were used: semi-structured interviews for employers and the focus group for community health professionals.

\subsection{Collection Tools}

Interviews were conducted in a face-to-face relationship or by telephone. For each group of actors, an interview guide was designed, then tested and validated.

An interview guide for community health professionals on the topics: matching theoretical and practical training in the field, professional integration.

An interview guide for employers (public sector or NGOs) on: quality and relevance of the skills retained within the framework of the teaching / learning program for these professionals.

\subsection{Data Collection}

\subsubsection{Semi-structured Interviews}

They concerned those in charge of the health system at the central, regional and peripheral level of the Ministry of Health and Social Action "MSAS" but also NGOs or one or more community health professional (s). They are also a target of great importance in so far as they are the users of the products offered by the Health and Sustainable Development UFR. They are the most apt to appreciate the contribution of these health professionals that they use. In addition, they can make proposals in case of revision of curricula so that training can meet the needs of the labor market. Appointments were made with these officials by phone call, facilitated by the director of the UFR. They were also informed of the objectives of the interview. Interviews averaging thirty to forty-five times were conducted over the telephone and were all recorded with their consent. Those responsible were selected by consensus by teachers from the community health department according to the objectives of the study. Thus, a representative sampling was carried out by choosing a manager for each level of the health pyramid and two NGO managers [11]. The choice of the person in charge is based on his seniority or professional experience, the number of community health professionals under his supervision, his availability, and his involvement during the development of the training model in community health. These interviews focused on the quality and relevance of the skills retained as part of the teaching / learning program for these professionals.

A total of five interviews were conducted and they involved three officials from the Ministry of Health (one responsible for the community health unit, one regional doctor, and one district doctor) and two heads of NGOs.

\subsubsection{Focus Group}

The focus group concerned community health professionals whether they have a license and / or a master's degree, working in the public or private sector. They are the first target especially as they are the main ones concerned.
Thus, interviewing them allows them to make an in-depth analysis of their professional career by highlighting the various problems they have been confronted with. They form a homogeneous group in relation to their training and profession due to sampling by homogenization [11]. The selection was guided by the pedagogical manager of the UFR SDD according to the objectives of the study. The choice of professionals was based on criteria such as the employer's status, place of practice, years of experience, gender, availability, type of activities carried out, position held. The focus group facilitator was also a community health professional who had to facilitate focus groups during his professional activities. It was the same for the observer taking notes. These professionals were contacted by telephone by the teaching manager of the UFR and all gave their consent to participate. In addition, he explained to them the expected objectives during this meeting. He made a telephone call back the day before the day scheduled for the focus group. The meeting place was set at the Dakar branch of Alioune Diop University in Bambey, easy to access and known to all. Three focus groups each comprising eight professionals were organized. In each group, there were also many professionals working in the public sector and in the private sector in particular NGOs. Each focus group lasted one hour and forty-five. The three focus groups took place successively during the day of a Saturday morning (day off). After the focus groups, a summary was carried out with the participants, followed by comments on the topic. The attendance sheet filled in by the participants included age, sex, place of exercise, position held, date of obtaining the diploma, date of recruitment and professional seniority easy to access and known to all.

The number of professionals was 24 with as many men as women; they had a minimum of two years' experience. These professionals worked both at the MSAS level and at the NGO level. At the level of the MSAS, they were divided between central, intermediate and operational level.

\subsection{Analysis}

The content analysis was carried out by a teacherresearcher specializing in sociology and officiating at the level of the community health department of the UFR Health and Sustainable Development "SDD" since 2012. She has proven experience in qualitative research and teaches this constituent element for undergraduate and postgraduate students from the same department. This analysis consisted initially in extracting verbatim transcriptions, the fragments or block of meaning most representative of the position of the person or group, also taking into account the facilitator's notes. After reading the interviews and focus group, the verbatim of the participants were classified in code according to their meaning in relation to the objective. The codes were then grouped manually into thematic categories established by the authors. An evolving thematic analysis, allowing an inductive approach to raw data, was carried out as the groups were carried out by the facilitator, using qualitative analysis techniques. The analysis of the content of the speeches 
illustrated by the words, put in quotation marks, of the people surveyed was carried out.

\subsection{Ethics}

Participation in the survey was purely voluntary and data collection was subject to rules of confidentiality (anonymization of recordings and transcribed data).

\section{Results}

\subsection{The Adequacy of Theoretical Training and Field Practice}

Community health professionals noted a match between theoretical and practical training in the field. In fact, they affirmed that the internships in healthcare and community settings have greatly contributed to making this professional training as evidenced by these verbatim: "The training allowed me to integrate well into my workplace. During the internships that I had to do, I gained a lot of experience so that I was able to calmly approach the professional environment itself "-" The training received in community health received at the university had an impact considerable in my professional activities. I acquired a good theoretical basis at the university which, added to the experience capitalized during the internships facilitated my integration into the workplace "-" It reminds me of my first job in the health district. As soon as I was assigned; the District Chief Medical Officer (MCD) appointed me focal point of the Expanded Immunization Program and the next day, I received 2 Head Nurses who needed inputs to carry out advanced strategies. They were formulating terms I had never heard of, and I had to validate the order. So I asked them to be patient and I locked myself in my office and suddenly I was starting to sweat, (I panicked) and luckily I was able to get through it just to say we have a good basic training. For some community health professionals, this training allowed them to occupy more positions of responsibility after their recruitment which affirms a participant "The multidisciplinary and operational dimension of our training allowed me to occupy several positions of responsibility going from the operational level to the strategic level of our institution. This transversality means that we can work in areas other than health, namely agriculture and the environment".

\subsection{The Need for a Review of the Training Model}

Community health professionals have judged that certain components of certain teaching units are less relevant, that is to say that they have practically no impact or contribution on their daily practice. They even proposed their removal. In addition, for better coherence, they expressed the wish to regroup the constitutive elements such as "community diagnosis, community participation and empowerment" since they have the impression of redundancy. The same is true for the constituent elements "employability, maintenance, communication". On the other hand, to make the training more operational, the participants proposed the reinforcement of certain constituent elements that they deem relevant: English, software, bibliographical references, epidemiology, statistics, scientific writing, research methodology, and management of the health information system". The words of a community health professional were illustrative in this regard "I suffered in my service when I received a visit from a team from Johannesburg in South Africa who spoke only in English. Communication was difficult and I often used body language to make myself understood. However, I had to explain our field activities to them at the request of my superior. Since then I have resumed my training in English". In addition, community health professionals have expressed the wish to integrate certain topical issues so that training can better respond to the needs and concerns of the populations; the themes cited were: "gender, urban health, adolescent health, one Heath, new software for collecting and managing data and epidemiological surveillance, financial management, coaching or management". The testimony of a participant is sufficiently symptomatic "in the institution where I was recruited I take care of adolescent health, I was confronted with the management of rape, homosexuality, drugs... At the start I suffered and I even wanted to resign but thanks to the support and support of my supervisor I got out, now it's okay. I was able to measure the extent of homosexuality in the peri-urban area when I had always denied its existence". A participant adds "after my recruitment, I was entrusted with financial management and monitoring / evaluation where I have to use software.

\subsection{Professional Integration at Two Speeds}

Community health professionals have judged that professional integration is done more easily in the private sector (NGO) than in the public sector (district level, regional level, central level) as evidenced by these remarks. NGO level and moreover all my classmates work with NGOs, on the other hand at the level of the health ministry, recruitment is rather timid and there are more contract workers". It happens that professional integration occurs after a period of volunteering according to some professionals, one of whom said: "You have to accept volunteering; in short you must always accept being exploited. Sometimes you can be in a structure, either we don't pay you or we just reimburse you for the transport, but if your supervisors see that you are really committed and essential, they will not hesitate to coopt you or even recruit you". Other professionals underlined that the integration can also depend on the competence and the proven commitment of the trainee said a participant "At the beginning of my internship no task was entrusted to me because the district management team was there and everyone had their program to manage. To satisfy my curiosity, I often approached the core team to immerse myself in their activities; it was afterwards that the Regional Chief Medical Officer (MCR) asked me to report on the various activities. What I did not regret because each time there was activity up to the central level, I was appointed to write the report. 


\subsection{Appreciation of Health Professionals' Community and Employers on Community Health Training}

Community health professionals affirmed that they have a good reputation with officials of state structures (district, medical region, ministry of health) and NGOs who, moreover, magnify their work and recognize their role and function in the sanitary system. These verbatim illustrate the usefulness of community health professionals within the health system. "Our work is well appreciated because very recently I was chosen with other colleagues by the Ministry of Health as speakers during the training for community surveillance, this proves that we are doing quality work ""My District Chief Medical Officer says that I am transversal because I work with the focal points of the various district programs (nutrition, malaria, vaccination) and he encourages me to continue in this direction "-" There is a good appreciation on the part of our employers, in particular the doctors in charge of regions or districts, which has earned us selections during the training courses that take place. The Ministry of Health and Social Action as a facilitator which is a source of satisfaction". These assessments are corroborated by doctors and NGO officials themselves. A doctor from the medical region of "Health professionals' community play an important role in the health system. They are well equipped for everything related to the community, they are also versatile. It is for this reason that we entrust health professionals' community affected in our supervision of health programs such as PEV, EPS.... and they do it to the satisfaction of their executive team region". A district doctor states: The community is transversal and in the district it works with the focal points of the various district programs (nutrition, malaria, vaccination programs) by ensuring supervision and monitoring and evaluation which allows us to make corrections". An official of an NGO states that "Health professional's community groups have proven their worth in the field, which is why we target them when recruiting and, moreover, in almost all NGOs they occupy operational and strategic positions.". He also declares: "The success of our health programs relies on community participation and engagement and on the ground health professionals community are formed to work with the communities and we are satisfied with their services"- "We let us now recruit health professionals community instead of relays or health workers community to raise the level of quality of our human resources in order to achieve our objectives"

\section{Discussion}

\subsection{The Adequacy of Theoretical Training and Field Practice}

The socio-professional integration of young people represents a real challenge for the future for the sub-region. Several works $[12,13]$ have been carried out on vocational training and apprenticeship for young people in Africa, but the issue of their socio-professional integration has so far not really been addressed. Many university graduates find it difficult to find a job since they have no profession at the end of their course $[14,15]$. To facilitate the insertion of these diplomas, the State has turned towards vocational training. This one is defined as training allowing an individual to acquire the specific knowledge and know-how he needs to exercise a profession. It is therefore traditionally associated with learning a trade, based on the practice and mastery of the technique rather than on theory and conceptual abstraction. [16]. Community health training is vocational training, that is to say, designed to allow graduates to find a job commensurate with their qualification upon leaving. It alternates theoretical training at the university and practical fieldwork (internships in health care, in community, in professional environment). The aim is to bring to the market community health professionals capable of solving population health problems with the communities. This strategy allows the learner to have skills. It is for this reason that the training model is co-constructed with external speakers and professionals and their concerns are taken into account and then validated by the teaching unit of the university. The national priorities defined by the Ministry in charge of Health and Social Action are integrated into the teaching of the various constituent elements. All courses are taught by professionals who have long experience in public health, particularly in community health. Some occupy strategic positions at the level of the Ministry of Health and Social Action, local authorities, development organizations and institutions. This training also calls on external contributors, from the professional world in particular the MSAS and NGOs. The program maintains close links with the professional environment as evidenced by the involvement of professionals in the development and revision of models and their involvement in the teaching and supervision of students. As soon as he is recruited, the graduate will not experience any difficulty in integrating into his professional environment which in fact is already familiar to him.

\subsection{The Need for a Review of Training}

Community health training is dynamic and must be readjusted to be attractive. It must regularly integrate new societal themes. The view of the alumni is fundamental to making corrections and rearrangements since they now have this field experience. To adapt training to market needs, a revision of the model based on the field experience of community health professionals is essential. Thus, teaching units can be proposed for deletion since they have no impact on professional activities. On the other hand, others can be reinforced to better equip the future professional.

\subsection{Two Speed Professional Integration}

Professional integration refers to the process allowing the integration of a person within the socio-economic system by the appropriation of the norms and rules of this system. [17]. Regarding graduate students in community health, it is easier 
at the level of the private sector (NGOs, Associations...) than at the level of the public sector in particular the MSAS and the NGOs.

At the private sector level in particular NGOs, the process is more flexible and there is recruitment as soon as there is a need. Thus, graduates respond to a call for applications for a previously defined position. The qualification required often matches the profile of community health graduates. Community health graduates are informed of the call for applications most often through their network. Indeed, they have an association with an electronic platform where all the information is shared; it is a form of solidarity.

At the level of the public sector, in particular the ministry of the civil service, recruitment follows longer procedures. Graduated students in community health like other university graduates submit their files to the electronic platform of this same ministry. There is recruitment as soon as the budgetary posts are available and each corps has a quota determined by MSAS. Thus, recruitment is not done according to needs like the private sector but according to the availability of financial resources.

Yet the RCMs and MCDs have expressed the need for community health graduates to strengthen the quality of their human resources. In this regard, the draft decree amending Decree No. 77-887 of October 10, 1977 on the special status of the framework of public health and social action officials validated by the Council of Ministers provides for the creation of professional bodies community health. They are community health advisers for master's graduates and community health workers for bachelor's graduates.

The creation of these two bodies will facilitate the integration of community health graduates into the public service.

In addition, the university has set up a service called Cellule - University - Company "CUE" to support students in professional life either in a company or towards selfemployment. To this end, the CUE offers workshops and counseling sessions that allow graduates to form a realistic vision of the world of work, so that they begin to design their future project in a realistic way, or at least a coherent training course in line with their aspirations and capacities.

\subsection{Appreciation of Health Professional's Community and Employers on Community Health Training}

Community health professionals make their contributions to improving the health conditions of the populations. These professionals integrate the health system most often at the peripheral level (health district or NGO) but also at the intermediate level (medical region) and central level (community health unit). However, the health system is more oriented towards curative activities (care, support) than preventive and promotional. Thus, prevention is the poor relation of the health system "prevention is better than cure" [18]. These community health professionals, by virtue of their competence, fill a deficit in qualified human resources. Their task will be to implement promotional, preventive and rehabilitation activities, but also community participation, these community professionals are able to solve population health problems with communities. Prevention and management with the populations of health issues being a solution recommended making our health system more efficient. These professionals will have the task of transferring their knowledge and skills to the community so that it can take charge and empower itself with the aim of community development.

\section{Conclusion}

The objectives of community health training are to put health professionals on the job markets knowledge and skills enabling them to contribute to improving the health of populations. It is an innovative but also professional training alternating theory and field practice. In fact, the training model is co-constructed between the teachers and the employers of the products trained (MSAS, NGO). Indeed, this training takes into account the concerns of employers. Indeed, community health is a Local approach to solving a community's health problems involving their active participation at all stages. It is theoretically implemented by a group bringing together professionals and the population. This training must be dynamic, which is why it must be regularly revised by integrating current topics.

\section{Recommendations}

1. Revise the community health model by integrating current themes;

2. Advocate with the Ministry of Health and Social Action for the recruitment of community health professionals at the public service level;

3. Organize "open house" days for greater visibility of community health training.

\section{Conflicts of Interest}

All the authors do not have any possible conflicts of interest.

\section{Source of Funding}

Supporting research work. The sources of funding are those coming from Unicef Senegal and the UFR SDD of the UADB.

\section{Acknowledgements}

Our thanks go to community health professionals and employers for their availability. We also thank the members of the UADB "health and nutrition" research team and "Health and Transitions in Africa" from UMI 3189 "Environment, Health and Societies". 


\section{References}

[1] Decree 2004 - 916 relating to "creation and organization of a CUR in Bambey, www.uadb.edu.sn/index.php/presentation/historique.

[2] WHO. The Community Health Worker, Practical Guide. Guidelines for training Guidelines for adaptation, Geneva 1987.

[3] A Crismer, JL Belche, J LV Vennet. Primary health care, more than primary care. Public 2016; 3 (28): 375-379.

[4] Sandrine Mohamed. What is community health? An example of a participatory and multisectoral approach in a municipality in the Canton of Geneva, Switzerland. Psychiatric information 2015; 7 (91): 563-567 https://www.cairn.info/revue-1information-psychiatrique-2015-7-page-563.htm.

[5] Renaudot Institute. Community health practice: from intention to action. Lyon: Éditions Chroniques Sociales 2001.

[6] Carole Dane. Empowerment a concept for France?. Social life 2007; 2 (2): 59 - 72 www.cairn.info >social-life-review-20072-page-59.

[7] Marie-Hélène Bacqué, Carole Biewener. Empowerment, a new vocabulary for talking about participation?. Economic and social ideas, 2013; 3 (173): 25-32. https://www.cairn.info/revue-idees-economique-et-sociales2013-3-page-25.html.

[8] Vanderveken Juliette (2018). The community approach: a methodology that promotes health? From social to town planning, including justice... all concerned! Health Education 2018 Number 343.

[9] Ministry of Health and Social Action, General Directorate of Health, Community Health Unit, December, National
Strategic Plan for community health 2014. www.sante.gouv.sn >sites $>$ default $>$ files>planssantcomun.

[10] Health pyramid of the Ministry of Health and Social Action $\mathrm{http}: / /$ www.sante.gouv.sn/politique-de-sante/pyramide-desant $\% \mathrm{C} 3 \% \mathrm{~A} 9$.

[11] Lawrence A, Palinkas, P, Sarah M. et al. Purposeful sampling for qualitative data collection and analysis in mixed method implementation researched 2015. https://www.ncbi.nlm.nih.gov/pmc/articles/PMC4012002/.

[12] Daffé G, Diagne, A. (Eds). Senegal facing the challenges of poverty, the forgotten by growth 2008, Paris / Dakar: Karthala-Cres-Crepos.

[13] Hamidou Dia. The return to the country of Senegalese graduates: between "development" and private entrepreneurship J. Int. Mobil 2015; 3: 115-128.

[14] François Dubet, Marie Duru-Bellat (2006). Controversy over the usefulness of La Découverte diplomas | "Revue du Mauss" 2006; 2 (28): 85 to 95.

[15] Romain Delès. Is the level of diplomas always a guarantee? Professional integration of students by level and degree specialties Agora debates / youths, 2013; 3 (65): 37-50.

[16] Law no. 2015- modifying the orientation law of vocational and technical training. http://www.mefpa.gouv.sn/wpcontent/uploads/2015/08/loi-d-orientation.pdf.

[17] Rhun B, Minni C (2012), "Integration of young people into the labor market: recent evolution of unemployment according to the level of education", Information Note, no 12.09.

[18] Directorate General of Health Community Health Unit, national strategic plan for community health 2014-2018 www.sante.gouv.sn/sites/default/files/BAT F Elected guide. 